\title{
Student Challenges with the University Access Program in South Africa
}

\author{
Lerato Sekonyela ${ }^{1}$ \\ University of the Free State, South Africa
}

\begin{abstract}
This paper reflects on experienced challenges by registered University Access Programme (UAP) students in South Africa. South African learners continue to face challenges in accessing institutions of higher education due to school performance. Therefore, to address this issue, the University of the Free State (UFS) in South Africa introduced UAP in 1993 to assist deserving students who did not meet university admission requirements due to underperformance at the school level. The UAP seemed to address the issue of access to higher education institution(s). However, once students gained access, they have faced several challenges. A Free-Attitude Interview (FAI) technique was used to identify the challenges that students experienced in UAP. Students indicated the need to improve academic support.
\end{abstract}

Keywords: academic support, university access programme, South Africa.

Even though the number of students who access higher education (HE) has seemed to increase in South Africa, several challenges remain to ensure adequate participation. This paper reflects on the challenges that UAP students have experienced to address this issue. UAP is a program that the University of the Free State (UFS) in South Africa introduced in 1993 to assist many deserving students who did not meet university admission requirements due to underperformance at the school level (Marais \& Hanekom, 2014).

In their studies, Jones and Lau (2010), Bathmaker (2016), Hlalele and Alexander (2012), and Karp, O'Gara, and Hughes (2010) identified similar problems and suggested the need for HEIs to address the challenges related to UAP students. One challenge that Hlalele (2010) identified was the unequal distribution of academic support. Other identified challenges included inequities in academic support, such as the scarcity of tutoring support, the need for peer support programs, and insufficient IT support and training. In addressing IT support, van den Berg, Verster, and Collett (2018) proposed, "Caregiving associated with the moral element of competence" (p. 444). Still, other challenges included campus segregation, the rareness of academic support centers, insufficient and limited academic advising.

According to Nel, Kistner, and Van der Merwe (2013), HEIs seem to have expectations of what students need to progress successfully. However, some institutions that offer UAP seem to prepare students inadequately and seem to have limited strategies that can enable student progression, and "these experienced and preconceived ideas have an important influence on the way that students handle the challenges posed by higher education" (Nel, Kistner \& Van der Merwe, 2013, p.85). Wilson-Strydom (2015, p.151) believes that to assess students' capabilities, we need to interrogate "whether different students have the same opportunities to achieve the outcomes."

\footnotetext{
${ }^{1}$ Correspondent Author E-Mail: letos@webmail.co.za
} 
Documenting these challenges is essential because the knowledge gained will allow institutions that offer UAP to realize the impact and the need to develop strategies to address these issues. These challenges potentially could hinder student success in the UAP and hamper the smooth transition of students to their preferred degrees, impact retention rates, and reduce successful qualification attainment.

Therefore, this paper focuses on two challenges, namely inequities in academic support and insufficient preparatory support programs. This paper illustrates how qualitative data could be used, using Participatory Action Research (PAR), to inform institution(s) of the challenges that UAP students experience, which will enhance an understanding and impact of the challenges, particularly in the South African context, and facilitate strategy development.

\section{Inequities in academic support}

Wilson-Strydom (2015) suggests that, although a policy to improve and increase participation has been implemented, more still needs to be accomplished. According to WilsonStrydom, participation has improved, particularly in South African universities. However, the question remains as to how institutions are going to retain their students. Therefore, a need exists to determine the kind of support provided to students that translates to successful qualification completion. In this context, Arendale (2010) raises the following pertinent questions: "Do students have the right to sufficient academic support?" (p. 14) "What happens when the services are not offered?" Similarly, Wilson-Strydom (2015) highlights an increase in inequity in HEIs, which seems to hinder student success.

Furthermore, O'Shea, Lysaght, Roberts, and Harwood (2016) raise the issue of social inclusivity. O'Shea et al. (2016) articulate that social inclusion in this context as ensuring equal opportunities that provide all members to participate fully as valued members of society. Therefore, students as members of society should not be marginalized by HEIs in terms of resource distribution, as HEIs also are parts of society, which need to perform particular functions for the whole to survive. O'Shea et al. (2016) pointed out that social inclusion is the responsibility of all institutions, including HEIs, as these institutions accept public funding. HEIs need to understand their students and have strategies associated with the realization of the capabilities of students. Thus, "support services should be boosted to help students manage dissatisfaction and to meet the rigorousness of academic life" (Gyamera 2018, 168). Additionally, Van Rensburg, Botma, Heyns, and Coetzee (2018) proposed "reflective epistemology," which involves facilitation processes.

These processes have the potential to provide students a sense of agency that allows students to respond, take action, and interpret their unique situations, which can facilitate the implementation of emergent ideas to resolve individual and unique learning opportunities. The following aspects are discussed to address inequities in academic support: 1) the scarcity of tutoring support, 2) the need for peer support programs, and 3) insufficient IT support and training.

\section{Scarcity of Tutoring Support}

Tutoring seems rare, regardless of the national context. In the United States, Karp et al. (2008) highlighted the significance of academic support, such as tutorials, that were inadequate at two community colleges (Northern Community College and Eastern Community College pseudonyms) they studied. Karp et al. (2008) further articulated that these community colleges offered students various support services, including tutoring. However, "with the exception of some programs targeting traditionally disadvantaged minorities and first-generation collegegoers, these services were open to everyone." In a study of the United Kingdom, Briggs et al. (2012) stated that incoming students value access to tutors. In their study of South Africa, 
Hlalele and Alexander (2012) believed that this type of support offered to students, needs to be scrutinized, and Bathmaker (2016) and Jones and Lau (2010) shared the sentiment that a need exists for tutorials in UAPs.

McFarlane (2016, p. 77) argued that "tutoring has an important role to play in enhancing students' learning experiences, and at its best, it has the potential to enable students to make connections between the different elements of the learning experience." Similarly, Waller, Mathers, Savidge, Flook, and Hamm (2017) acknowledged that knowledgeable students should conduct tutoring with valuable resources that would otherwise be less accessible and boost academic performance at the UAP level; thereby increasing access to Higher Education. Kaldi and Griffiths (2013) attributed performance and success to a range of institutional influences, one of which was support by tutors. Kaldi and Griffiths (2013) also affirmed that learning from tutors provides an additional positive influence on learning and student success.

Furthermore, "the role of the tutor is central to enhancing the student experience and fostering student retention by providing personal contact" (McFarlane 2016, p. 78). A tutor can act as a link or go-between "between the student, the curriculum, and pastoral support available and to engender a sense of belonging, which is crucial to student engagement, particularly in the first year" (McFarlane, 2016, p. 78). Tutoring needs to focus on reinforcing and extending subject knowledge, and additionally, on remedial work, revision guidance, and examination techniques that would facilitate and improve student success (Waller et al., 2017). MountfordZimdars, Sanders, Moore, Sabri, Jones, and Highamby (2017) maintained that institutions could further support students by focusing on curricula and learning, extracurricular engagement, and building supportive social relationships.

\section{Need for Peer Support Programs}

UAP students need organized and structured peer-support, which currently seems insufficient. Briggs et al. (2012) believe that support systems enhance socialization and adaptation. "Contemporary notions of the student experience extend well beyond the traditional focus on curriculum, assessment and pedagogy to include extracurricular activities. Extracurricular activities should form a vital part of students' experience to create good opportunities for friendship and learning" (Gyamera 2018, p. 168). There is also a need for student peer coaches. Supportive systems can take the form of "staff as course co-ordinators working with small groups of first-year students" (Briggs et al., 2012). This kind of support system is evident in the UAP but seems inadequate due to time constraints. Facilitators do not have enough time to pay attention to every student, even if the groups are small (Garbe et al., 2020).

Several factors are at play for students to be successful in their academic and personal spaces (Camarero-Figuerola, et al. 2020). These factors range from institutional influences to non-institutional influences, such as peer networks (Kaldi \& Griffiths, 2013; Monkeviciene et al., 2020). Kaldi and Griffiths (2013) further point out that collaborative factors such as peer learning are particularly beneficial for students. Gale and Parker (2014) noted that students could find the first year of HE quite challenging. Gale and Parker (2014) further drew "attention to the situational difficulties, that is, it is not only a change of the type of study situation, with higher demands on students' use of time but also a new social situation and new friends" (p. 743). Some students struggle to fit in and cannot relate to the UAP culture. Some students find it challenging just to be in a UAP as they have difficulty associating with persons from different backgrounds. Similarly, inadequate social activities that are supposed to aid students in meeting and interacting with others make the life of a UAP student even more challenging. Activities 
such as peer network spaces should be made available to enhance student engagement because these are likely to have a positive influence on their academic performance.

Tutors can help facilitate peer networks where students share knowledge, collaborate in lesson planning or other assignments, and communicate socially with their peers. Through these networks, students can exchange news and knowledge about courses (Kaldi \& Griffiths, 2013; Loh \& Ang, 2020; Palmer \& Witanapatirana, 2020). Institutions can initiate peer network schemes to benefit students in progressing successfully through higher education by providing role models and peer-support. Thus, peer network schemes can assist UAP students because these students feel that they do "not fit in, that their social and cultural practices are inappropriate and that their tacit knowledge is undervalued, they may be more inclined to withdraw early" (Gale \& Parker, 2014, p. 743). When a student can easily access a peer network where she/he can share experiences, that student may realize that she/he is not alone, and assistance is easily accessible.

The UAP does not have structured peer networking spaces where students can share knowledge. Consequently, this absence leads to voiceless students as they are informed of what needs to be done in terms of their academic activities but without input from their side. O'Shea, Lysaght, Roberts, and Harwood (2016) conducted a study at an Australian university, and they came to the same conclusion. According to Speirs et al. (2017), "a way to foster student engagement is to promote ecological learning systems, where emphasis is placed on the ways in which individuals interact and develop. Within these interactions, it is important that the student voice is present, in order to lead to a radical collegiality that redefines the traditional student-tutor relationship" (p. 52). This will, in turn, promote peer learning. Also, peer learning can be used and seen as "reflective learning," in that students can be able to demonstrate problem solving and critical thinking and learn from and with each other (Van Rensburg, Botma, Heyns \& Coetzee, 2018).

Insufficient peer networking spaces bring about some challenges. For example, UAP students seem to lack a sense of belonging in that they do not engage with students from other campuses or even with students on their own campus. They are further not awarded space for engaging out of class, as they do not participate in activities other than their academic activities. These activities can potentially provide space for first-year students to engage with senior students, which can lead to the sharing of experiences, challenges faced, and the mechanisms used to overcome challenges. Speirs et al. (2017) pointed towards radical collegiality, acknowledging the "power of peer learning" as students and lecturers co-learn, and finally, considering education as "a democratic project."

Furthermore, O'Shea et al. (2016) highlighted that first-year students, particularly those who did not meet university requirements, experience "difficulties of fitting in with the university culture." O'Shea et al. (2016) added that "most first-year students experience feelings of isolation and loneliness" and that students who "differ from the mainstream experience intensified feelings," such as UAP students (p. 324). "Certain skills and knowledge are socially embedded and depend on access to appropriate capitals in order to enact appropriately" (O'Shea et al., 2016, p. 324). Therefore, students need space to engage with their peers, which will aid in a smooth transition and easier adaptation to the HE culture.

Speirs et al. (2017) concluded that an institution needs to believe in the power of student agency, and in particular, the importance of students as partners and co-creators. Arnold and Clarke (2014) commented on how the term agency "lacked explicit operationalization." Therefore, Arnold and Clarke preferred to think of agency as a combination of two things, namely, projectivity or the capacity to fulfil one's goals while acting under a set of personal values and opportune circumstances. Opportune circumstances can lead to the exercise of agency by an individual. UAP students need a sense of agency because agency is a vital element linked to the easy navigation of a university's culture. However, because UAP students seem to do as they are told, they are voiceless, making it even more difficult to adapt to this foreign 
environment. This strengthens the need for a structured or formalized peer support network in a UAP.

O'Shea et al. (2016) believe that the inequality that exists within HEIs cannot only be ascribed to student deficits, as "it is possible to attribute it to individuals or to institutional practices that unintentionally create circumstances that result in inequalities" (p. 325) Therefore, Gale and Parker (2014) suggested 'social integration and academic performance' as contributing to attrition; and that "both are required for the successful integration of first-year students" (p. 740).

\section{Insufficient IT Support and Training}

HEIs seem to function under the false assumption that all students who gain access to the institution are computer literate and expect students to perform online assessment right from the start of their academic career. Unfortunately, many students, especially UAP students, are poorly equipped to deal with computers and technology, as they have not had sufficient training in this regard. Hansen and Reich (2015) revealed a "gap in education technology opportunities between students from different backgrounds" (p. 1245). This gap is "best understood as two divides: one of access and one of usage" (Hansen \& Reich, 2015, p. 1245). Hansen and Reich (2015) further stated that "affluent students not only have different levels of basic access to technologies, they have used them for different purposes with different levels of support" (p. $\mathrm{x}$ ). Thus, technology usage at HEIs seems to perpetuate further the marginalization of students, particularly UAP students who are categorized as under-prepared for HE as they did not meet the university admission requirements.

HEIs must consider the different technology backgrounds of their students to avoid advantaging one group over another. For example, students from model C schools are "likely to use computers for simulations or modeling, while students from schools serving low-income students likely use computers for practice exercises" (Hansen \& Reich, 2015, p. 1245). In this regard, HEIs must equip students as soon as they enter HE to use technology to their advantage and enhance their academic performance. Van den Berg, Verster, and Collett (2018) proposed, "Care-giving associated with the moral element of competence" (p. 444). Additionally, Tronto (2013) elaborated that caregiving requires one "to be competent to care" and is "not simply a technical issue, but a moral one" (p. 35). Tronto (2013) qualified competence as including caregiving that addresses accessing materials and resources such as time and skill.

Hansen and Reich (2015) found that "free wikis were more likely to be created in affluent schools, and in these schools, wikis were more likely to be used to support collaborative problem-solving and new media literacy. In schools serving low-income students, wikis were more likely to be used for teacher-centered content delivery" (p. 1245). Therefore, students from non-model $\mathrm{C}$ schools might be under the impression that only academic staff has access to technology. UAPs must equip and train students, preferably in the first semester, in using technology to enhance their HE experience and better their academic performance.

According to Smith, Trinidad, and Larkin (2015), online education and digital learning have become the norm among educational institutions, specifically HEIs. However, the relationship between communities and educational institutions needs to be re-visited. "The digital revolution can provide digital learning opportunities for disadvantaged and advantaged students, provided students have access to such opportunities, and their engagement is supported" (Smith, Trinidad \& Larkin, 2015, p. 22). Therefore, HEIs should move away from the assumption that all students possess a computer or a smartphone and that all students can use such technology if made available. 
Therefore, participation in and access to HEIs must be based on inclusion, where all groups are given the same opportunity to utilize resources from which they can benefit, and equity should be aimed at reducing the barriers that can impact success (Nelson \& Creagh, 2013; Olga et al., 2021; Rawlinson \& Willimott, 2016). Hlalele and Alexander (2012) indicated that there is evidence that "students in some quarters of the education system frequently experience negative and inequitable treatment" (p. 487). Hence, scholars who theorize inclusion call for students never to be seen in isolation. In other words, all students need equal treatment, and the campus they attend should not be a defining factor for access to resources. Additionally, the notion of participation is central to understanding the notion of inclusion (Hlalele \& Alexander, 2012).

Institutions must "advocate adequate mechanisms to regulate social arrangements in the fairest way for the benefit of all" (Hlalele \& Alexander, 2012, p. 489). Furthermore, Hlalele and Alexander (2012) noted that "regulating social arrangements could mean dismantling institutionalized obstacles that prevent some people from participating on a par with others as full partners in social interaction and accessing beneficial resources such as technology" (p. 489). Therefore, students as agents and stakeholders in HEIs need to "advocate the discourse of disrupting and subverting arrangements that promote marginalization and exclusionary processes" (Hlalele \& Alexander, 2012, p. 489).

\section{Preparatory Support Program}

In this paper, preparatory support refers to access to beneficial resources that assist students in adapting to the HE environment and consequently lead to progression to the next level. Students experience several challenges in terms of preparatory support, such as segregation of physical environment and resources, the invisibility of learning support center, and limited and inadequate access to academic advising. However, this is not a comparative study. It is significant to highlight this because institutions that offer UAP seem to be multicampused.

\section{Physical Environment and Resources}

Often, the UAP is offered on a different campus than the campus at which mainstream students are accommodated (Arendale, 2010). This practice is evident in some South African universities like the University of the Free State (UFS) and the University of KwaZulu Natal (UKZN). Segregation of campuses appears to perpetuate exclusion and marginalization of UAP students as most support services, if not all, are located at the mainstream campus.

Most higher education institutions that offer access programs do so at a different campus than the mainstream campuses. This isolation and segregation affect not only students who academically failed to obtain the required admission points but also the academics associated with these programs. This segregation and isolation perpetuate further stigmatization (Arendale, 2010; Jones \& Lau, 2010). For example, most beneficial resources are located at the mainstream campus and are associated with or potentially lead to successful academic performance. Therefore, a UAP campus without such resources may hinder students in realizing their full potential, consequently leading to attrition and possibly general stigmatization of the UAP. Furthermore, due to segregation and/or isolation of campuses, some students may feel disconnected from their studies and the institution.

UAP campuses seem segregated and under-resourced (Bathmaker, 2016; \& Mabila et al., 2006). For Mabila et al. (2006), under-resourced perpetuate unequal resource distribution, limited availability, and limited accessibility. Unequally distributed resources range from access to tutors, peer network spaces, academic advising, and a learning support center. UAP students potentially suffer as a result of said under-resourced campuses. Therefore, Peck et al. 
(2010) highlighted the importance of the availability of programs such as the Academic Learning Support Assistant (ALSA) and its location. ALSAs are programs developed to support students in academic matters and, therefore, should be located in a single area, allowing easy access for students. For that reason, both the UAP and the mainstream programs can be offered on the same campus to ensure the availability and accessibility of beneficial resources.

Gale and Parker (2014) recognized several beliefs about learning and knowing, which currently dominate HE. According to Gale and Parker (2014), these beliefs are socially exclusive and require students to adopt identities that do not always agree with their life trajectories. As a result of their academic performance in school, students in the UAP often find themselves enrolled in a field of study because they qualify for enrolment and not because that is their program of choice. Therefore, Gale and Parker (2014) suggested: "a more socially inclusive regard for university student identities and practice that would acknowledge that the curriculum itself should reflect and affirm working-class students by ensuring that workingclass histories and perspectives are presented with respect rather than marginalized and ignored" (p.743). This inclusiveness could be achieved through the availability of learning assistance centers and/or other spaces to support students, thereby fostering a smooth transition to HE.

Integration of campuses that provides the student cohort access to all beneficial resources that the institution offers may increase student engagement and provide a sense of collegiality. Inevitably, this integration can promote inclusion and discard feelings of marginalization that some UAP students have experienced.

\title{
Learning Assistance Aupport Center (LASC)
}

According to Northall, Ramjan, Everett, and Salamonson (2016), university academic expectations are quite different from vocational education and training (VET). Northall et al. (2016) stipulated that students often

\begin{abstract}
struggle with academic referencing, essay writing, and using information technology (IT) sources. Therefore, this assertion calls for the availability of and accessible learning assistance support centers. Vocational pedagogy is traditionally competency-based and focused on the teaching and learning of a trade, whereas university pedagogy is geared towards deep learning with a theoretical orientation that encourages critical thinking, reflection and action (p. 27).
\end{abstract}

The expectations from higher education studies challenge most students, and without learning assistance support centers, these students may feel overwhelmed and become disconnected from the environment. In some cases, this leads to a failure to complete a program. Without access to learning assistance support centers, students can feel unprepared to handle the challenges and perform to the expectations of the institution. This, together with limited knowledge of resources or university systems, potentially can be a barrier to the retention and success of these students (Northall et al., 2016). Therefore, UAPs should introduce learning assistance support centers to prepare and assist students with academic-related matters. Northall et al. (2016) found a similar issue in their study that involved a metropolitan university in Western Sydney.

Furthermore, invisible learning assistance support centers deny students the opportunity to uncover their potential and identify areas that need growth and development. Peck et al. (2010) indicated that the availability of ALSA at Roehampton University was beneficial. Thus, 
a need exists for such centers to assist students with academic writing matters. ALSA provides similar services like the Centre for Teaching and Learning (CTL) at the UFS. However, from Strydom, Du Plessis, and Henn's (2016) study, it is evident that CTL caters only to mainstream and extended program students. In reality, UAP students are in dire need of these services. Another issue is that CTL is located on the mainstream campus, quite a distance from the UAP campus. Franklin and Blankenberger (2016) documented the need for Learning Assistance Centres (LACs), which seem to provide a wide range of services similar to ALSA and CTL.

Gyamera (2018) suggested that the universities should encourage students to engage actively in co-curricular, including clubs, debates, and cultural group celebrations, to complement the classroom experience and build community. Furthermore, Gyamera put forth the need for universities to boost social activities; this boost can be brought by establishing centers for student engagement. One function that these centres can perform is to advise student organizations and help develop various programs.

For Nel et al. (2013), language is one of the biggest obstacles that students enrolling in higher education studies face. Nel et al. (2013) suggested that students, before and after enrolling, could benefit from psychometric assessment, subject choice or career advice, and counseling. Institutions can, in advance, identify areas that students may need an introduction to upon enrolment, for example, computer literacy. These forms of assessments have an important influence on students' subject choices and can contribute to student academic success in their proposed higher education studies. However, institutions may have to develop facultyspecific assessments based on the needs of the faculty. Similarly, in UAP, a need exists for faculty-specific academic advising for all students, especially first-years, despite their educational background.

\section{Academic Advising}

Karp et al. (2008) found that some colleges offered students various support services at different centers, for example, program advising. One risk associated with program advising is that every time a student needs academic advice, that student may meet a different advisor than the before. This lack of continuity may lead to misdirection as students are exposed to general advising and not faculty-specific advice. This process can result in a depersonalized relationship between the advisor and the students. Therefore, faculty-specific advisors and increasing the number of advisors are vital. This is similar to the situation in the UAP, as there seems to be limited access to academic advising support. Strayhorn (2014) highlights the following as key responsibilities of advisors: "They help make the implicit explicit, the hidden known, and the unfamiliar commonplace. They help students navigate college by making clear what students need to know and do to be successful. They help students find a sense of belonging on campus" (p. 62). Therefore, there seems to be limited access to academic advising support in UAP, and this deficiency denies students a sense of belonging and may hinder a smooth transition to the mainstream.

Kirk-Kuwaye and Sano-Franchini (2015) indicated that academic advisors could guide students in carefully choosing general education courses, provide knowledge and awareness that would enhance student core beliefs, and prepare them to face the ethical and societal issues of their future profession. However, without access to such support, UAP students may feel neglected and find themselves functioning in isolation. Some UAP students may continue their studies with one goal in mind, namely the successful completion of a qualification, and fail to find a connection between what they study and their purpose in life. Through academic advising, UAP students can understand what they are studying and why, enhancing their engagement in the general education environment (Egan, 2015; Kirk-Kuwaye \& SanoFranchini, 2015; \& Lowenstein, 2015). 
Aguilar, Lonn, and Teasley (2014) evaluated the use of the Early Warning System (EWS) by academic advisors in the United States. They found that the "EWS intended to support just-in-time decision-making around students' academic performance for use by academic advisors within two specific Science, Technology, Engineering, and Mathematics (STEM) learning communities" (Aguilar et al., 2014, p. 113). The implementation of this system seems to be timely to support students who are struggling academically; however, the system seems to be marginalizing in nature as it caters only to STEM students.

A similar system is present at the University of Limpopo in South Africa, namely the University of the North Science Foundation Year (UNIFY) (Mabila et al., 2006). One aspect of concern regarding these kinds of systems is that it seems as if they are intended to prepare students in courses such as mathematics and sciences only. Other fields of study seem neglected. This raises the question of whether South African HEIs still hold the traditional notion that only students who excel in mathematics and sciences are intelligent. Seemingly, UNIFY also holds the notion that mathematics and science are the only important subjects, and by doing so, they give the message that all other fields of study are useless. Once again, this perpetuates the system of marginalization and exclusion that needs to be addressed. Therefore, increasing the number of and accessibility to academic advisors in the UAP may be one answer as it places advisors in a position to identify difficulties and challenges students' experience. Thus, stakeholders can be made aware of these issues, thereby facilitating appropriate facultyspecific mechanisms. Similarly, Bicer, Lee and Perihan (2020) study found that STEM "focused more on science and mathematics than other disciplines like English and history" (p. 158). If STEM focuses more on other disciplines, how do students find a balance? What is done to address other disciplines? What message is being delivered here? What remains is that, there seems to be initiatives and programs addressing science and mathematics, and neglecting other disciplines.

Darling (2015) contended that academic advisors play a vital role in HEIs, as advisors can inform academic staff or colleagues of the challenges students face, the experiences students have outside the classroom, and how these challenges affect the students' learning and success. Another concern is that, although the academic advisor is available, she/he must also be effective in advising students (Darling, 2015). Academic advisor(s) on UAP campuses are only available for a limited period and, in most cases, advise all students on campus. There seems not to be any faculty-specific advisors, which needs to be addressed (Egan, 2015; Lowenstein, 2015; Karp, O’Gara \& Hughes, 2008). Advisors on UAP campuses should not only be available during the registration period but for the full academic year. Furthermore, the institution needs to establish a connection between the advisors and the academics, as academic staff members may feel bombarded by students with personal issues. Therefore, institutions need to establish clear responsibility, that is, are these responsibilities of the advisor and /or counselor.

\section{Participatory Action Research}

Participatory action research (PAR) was chosen as the research methodology in this study as one purpose of PAR is to improve the quality of people's organizations and lives. Furthermore, researchers who employ PAR study issues that relate to social problems that constrain and repress the lives of students and educators (Creswell, 2012). Marincowitz (2003) indicated that PAR is a research process that focuses on improving the quality of service utilizing a self-reflective process, exploring and problem solving. Similarly, Ary et al. (2010) articulated that PAR is emancipatory and transformational and aims to challenge unproductive ways of working. PAR seems aligned with critical reflectors. Critical reflectors engage in 
multiple ways of knowing, which facilitates new perspectives that inform future actions and practices (Van Rensburg, Botma, Heyns \& Coetzee, 2018)

Jacobs (cited in Plooy-Cilliers, Davis \& Bezuidenhout, 2014) stated that PAR is used to study social issues that constrain the lives of individuals and that one defining factor of PAR is its collaborative nature. In the PAR environment, collaboration is vital as the researcher and coresearchers are viewed as equals, with minimal power dynamics. In other words, "equality in sharing control and power is a basic value in PAR" (Marincowitz, 2003, p. 595). Babbie (2010) articulated that PAR often involves poor people who have little influence on policies and actions that affect their own lives. Also, Glassman and Erdem (2014) articulated, in PAR, "the research is a collective problem-solving process in the shared real world, where all actors (those affected) are involved in research" (p. 215). Seemingly, PAR has a similar characteristic as reflective epistemology; that is, students' experiences and perceptions are essential in knowledge development and positioning (Van Rensburg, Botma, Heyns \& Coetzee, 2018). For some authors like Van Rensburg et al. $(2018,608)$, this way of gaining information is referred to as "storytelling." The commonality between PAR and storytelling is that both allow for the formation of new knowledge.

\section{PAR Process Followed in This Study}

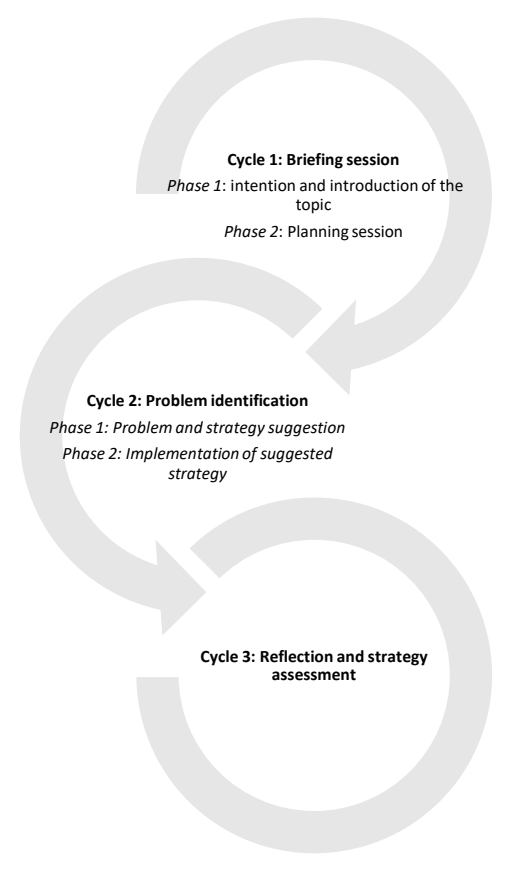

\section{Data Collection}

Data were collected through focus group discussions facilitated by the Free-Attitude Interview (FAI) technique (Nkonyane, 2014; Mahlomaholo, 2009). A focus group comprised of registered UAP students. During discussions, several themes and issues were raised; one that stood out was that students felt the need for academic support to improve. In their view, they hold the belief that improvement in academic support will facilitate and help them realize their capabilities. Focus group discussions provided space to discover information that one would not otherwise access. That is, it was easier for other people to voice their concerns when they realize that others have similar experiences. Therefore, the co-researchers were more comfortable speaking out and engaging in discussions; they also provided evidence to reaching conclusions from post hoc analysis of separate statements from each interview. FAI seem to employ a "reflective storytelling technique" as students present the "human side of education 
and demonstrate some of the deeply personal and individual stories and become both a studentsupport strategy and a learning activity" (Van Rensburg et al., 2018, 608)

Focus group discussions worked well with Critical Discourse Analysis (CDA), which this study employed. Central to CDA is the understanding that discourse was an integral aspect of power and control. This method was chosen as it allows the researcher and the co-researchers to take control of the discussion, and no one felt forced to say something that they were uncomfortable sharing with the group (Babbie \& Mouton, 2005; Lazar, 2005).

CDA seems to employ what Van Rensburg et al. $(2018 ; 610)$ refers to as a critical incident. Van Rensburg et al. $(2018 ; 610)$ defined a critical incident as "a specific technique in reflection where students are asked to describe and analyse a particularly meaningful incident they have experienced or observed in the learning environment" (p. 610). FAI and CDA enabled knowledge creation and informed critical aspects pertaining to the study (Lazar, 2005; \& Weninger, 2012). Van Rensburg et al. $(2018,605)$ posited that some requirements of "studentsupport strategy reflection" are deliberate planning and active participation of all stakeholders, particularly students. This could mean that a PAR researcher assumes a facilitator approach characterized by "being present but not to prominent, provide a balance in the support by giving responsibility (to students) and having control (of the activity and learning) and creating a space for reflective practice to flourish" (Van Rensburg et al., 2018, p. 605).

The planning the schedule was designed so that the timeframe of the sessions suited everybody. The sessions took place on the premises of the university to avoid any form of inconveniences, such as travel time or unfamiliar places. The following are some of the ethical considerations that were put in place, namely, voluntary participation, voice recording, informed consent, no harm to any participant, and gatekeeping approval.

\section{Students at the University of the South (Pseudonym)}

In this research study, the participants or co-researchers are current UAP students. The researcher purposefully chose the co-researchers based on the following characteristics (Pascoe, 2014; Strydom, Fouché \& Delport, 2004; Wildemuth, 2009): co-researchers are currently UAP students, registered in the Faculty of Humanities, with Sociology as a major. The guiding primary consideration was that these students would provide insightful information related to the topic as they are currently experiencing the challenges of a UAP (Wildemuth, 2009).

From a functionalist point of view, social reality is largely what people perceive it to be; it exists as people experience it and assign meaning to it. Social reality is fluid and fragile, and people construct it as they interact with others in ongoing processes of communication and negotiation. Furthermore, functionalists also believe that social life arises in people's subjective experiences as they interact with others and construct meaning. Therefore, the participants, as registered UAP students, were in the best position to provide insightful information of their experiences and challenges, which would consequently give light to the development of strategies.

In this study, participants are referred to as co-researchers as they collaborate in exploring and identifying problem(s). This entail all actors' involvement through the process, this also minimize power dynamics, which could hinder participation. The co-researchers were sourced from UAP-UFS in South Africa. For the purpose of this research study, ethnic grouping did not play a role in determining co-researchers, as South campus as a research site consists of different ethnic groups (Sotho, Xhosa, Venda, Zulu, and Afrikaans). Therefore, all students with Sociology as a major had equal opportunity of participating in the study, despite their ethnic group. Informed consent forms were given to students to take home, it was done in this 
manner for students to decide voluntarily to participate. Once the forms were returned back, consent was gained to voice record discussions. Before discussions commenced, each coresearcher was given name (pseudonym) that will be used for findings dissemination at a later stage. The following names were given and have been grouped according to gender females (Kate, Mamello, Lydia, Boitumelo, Thato and Luyanda), and males (Zizi, Thabang, Sizwe and Edward), this was to maintain anonymity.

During sessions or discussions (focus group discussions), the researcher and coresearchers took steps to ensure minimal interruptions. The telephones were switched off and a 'Do not disturb' sign was placed on the door to keep uninvited guests from entering. There were ten (10) co-researchers ( 6 females and 4 males) present in the discussions. I saw the need to conduct this study as a former UAP student, and currently employed at the same program, and because I realized that not much has changed from when I was a student.

\section{Limitations of the Study}

A number of limitations and challenges were experienced during the course of this study. Some students suggested that while the researcher was inviting participants for the study, UAP facilitators indirectly advised students against participation. Students were indirectly informed that during research processes, students are exploited, therefore some students decided not take part in the research study.

Other challenges included mistrust between co-researchers and fear of victimization. Other co-researchers indicated that they had to lie to friends about their whereabouts because they were uncomfortable with the thought that their facilitators may discover that they are getting help elsewhere.

Venue allocation also posed a challenge as the researcher was informed that she could not be allocated a venue within the university vicinity as the study was personal and not related to the students or her work.

There was a time limit regarding the implementation of the strategy to improve academic support. The research schedule had to be aligned with the schedule of the specific module, and as the students were also committed to their other modules, the sessions were extended and often held after hours.

The researcher intended to have a working space or venue where students could sit comfortably while working, have activities printed and stationary to use during sessions. Unfortunately, the researcher could not find a sponsor. Therefore, lack of funding can also be a limitation.

The co-researchers also had other expectations from the researcher. One particular incident that stood out happened after the students had been informed that one faculty has decided not to admit students from any other faculty. The co-researchers suggested that the researcher negotiate on their behalf. However, the researcher informed them that this situation was out of the researcher's scope of work, and that it was the academic advisor's responsibility. A meeting was scheduled between him and some of the co-researchers to discuss the matter.

\section{Functionalism as Framework}

Functionalism posits that for society to thrive and function smoothly, all parts need one another. Based on this premise, functionalism was employed as a theoretical framework. Functionalism shows that when all parts exist within an institution function interdependently, the institution functions smoothly, and equilibrium is maintained. Hence, functionalist proponents point to the performed functions and dysfunctions within social institutions. According to these proponents, functions and dysfunctions help maintain equilibrium, order, and stability (Benokraitis, 2016; Ferrante, 2016; \& Henslin, 2008). 
Functions are defined as acts performed to reach desired outcomes, and functions can also be unintended (Benokraitis, 2016; Ferrante, 2016; \& Henslin, 2008). Merton (cited in Benokraitis, 2016, Ferrante (2016), and Henslin (2008) categorized functions into manifest functions and latent functions. Society has expectations in terms of certain functions that institutions of higher education need to perform; however, dysfunctions within institution(s) should and cannot be ignored. Merton (in Benokraitis, 2016), Ferrante (2016), and Henslin (2008) view dysfunctions as institutional actions that can disrupt the smooth functioning and well-being of the whole system. Lack of academic support may also lead to student attrition, albeit an unintended consequence (Benokraitis, 2016; Ferrante, 2016; Henslin, 2008).

\section{Findings (names - pseudonyms)}

As state earlier, to maintain anonymity, the following pseudonyms were used and have been grouped according to gender females (Kate, Mamello, Lydia, Boitumelo, Thato and Luyanda), and males (Zizi, Thabang, Sizwe and Edward).

\section{Limited Tutoring Support}

Limited tutoring support is used to refer to lack of access, formal and structured tutoring services. In this regard, students described the nature of academic support at the UAP. This is how they responded (Zizi and Thabang):

We need help, any kind of help because we want to understand the work. We do not know what UAP can offer. All we need is any kind of help....

At some point, because we need help, we hustle for help, we were even planning to look for a tutor, but it did not work out.

Accessibility. The above statements clearly show that students valued tutoring, and saw the need for such services to enhance their learning and understanding of course material. They highlighted that as students, they could benefit greatly from tutoring as it awards them the opportunity to overcome disadvantages. One student further articulated that:

...we are from high school and some of us from rural areas where we were told many times that we're are not good enough. In high school, we were spoon-fed, but varsity is another level. We have to be independent. No one will chase after you asking why you did not do the work. Some of us come from rural areas. This environment is new to us. We don't know what is expected of us... Facilitators act like we know, we as students are like small children/baby. You can't force a small child to eat pap and spinach....we are like small children; it's the first time at university, so facilitators should first give us information, help us understand, let us ask questions..... we do not have tutors here.

Formalised and structured support services. Students should be informed of all available support from the onset of their academic career at a university. Drawing from the perspectives of the students, the conclusion can be reached that students were not informed of such support; it could be that there is no support offered, therefore there was nothing to tell the students. Therefore, the students felt stranded and alone in a new environment. The students 
also indicated that some facilitators were unapproachable, making adapting to university life even more challenging. From a functionalist perspective, when systems within an institution do not function interdependently, the institution, referring to both students and other stakeholders, is damaged.

\title{
Need for Peer Support Programs
}

Peer support programs needs to be supportive in nature, afford collaborative space for learning, and allow students in participating in curricula construction.

Supportive. Several factors at play need to be considered for students to succeed in their studies. If students play a role in the co-creation of curricula in subject related matters, they experience an increase in engagement and motivation. The discussion, in this case, was based on how they study, and whether as students, they help each other. All co-researchers (Zizi, Thabang, Kate) indicated that since this study started, they have learned to rely on each other for support. These responses stood out

\begin{abstract}
Me...since you started this group, as a group, if we work together, we can make it, and pass with flying colors...... when we leave this campus, like in this group, we are working together in different modules, it helps.
\end{abstract}

We do work together as a group in different modules. When we work together, the other students explain in our language (referring to mother tongue) ... in that way, things are easier to understand.

...since we started working with you, we now know who (referring to group members) is good at what subject or part of the module; therefore, this helps because we talk amongst each other and help each other.

The above statements show that students greatly benefited from working together. When students are provided a peer network opportunity, they communicate knowledge and collaborate in sharing and suggesting different ways of approaching individual subject matters. Students further benefit as they support each other, confirming the need for peer networking.

Collaborative learning. Additionally, students stated that peer networks help them to socialize and adapt to this foreign environment. Furthermore, students articulated that peer networks allow them to co-create curriculum or co-grade subject related matters. Co-creation of curriculum and co-grading seem evident in the following responses by Lydia, Boitumelo and Mamello:

Yes...I do formulate own questions; it helps. I read everything, then record self, especially with long questions, and it works.

...it helps when you have someone who challenges you to see whether you understand. That is why we come up with different questions and try to answer them, just in case they are in the test.

We also ask you, ma'am, to check if we have approached the questions right.... to see whether we understand and are on the right track. 
Constructors of curricula. The above responses demonstrate that students developed their own questions and worked on answering such, thereby engaging in co-creating or cograding of subject-related matter. In a way, students developed their own question papers and memorandum, which facilitates the learning process. Therefore, when students are afforded space to collaborate and work collectively, they learn better and experience increased motivation and engagement during and after facilitation sessions. This agrees with functionalism in that when all parts co-exist and no individual exists in isolation within the institution, they will maintain a smooth transition, and the whole has a better chance of survival.

\section{Insufficient IT Support and Training}

Insufficient IT support and training, used to refer to lack of spaces that allow for interactive, fused learning, and lack of just in time training.

Interactive learning. A gap in education technology opportunities for students from different backgrounds is evident. This gap is two-folded: "one of access and one of usage," that is, students from different backgrounds might have or have no exposure to technology. Furthermore, they also might have or have no access to different types of technologies. Therefore, UAPs need to be mindful that there are students from backgrounds who have never sat in front of a computer, let alone know how to switch it on or use the keyboard or mouse. Therefore, without prior training in technology usage, one group might benefit over the other, hence the need for training at the beginning of the academic year. The students (Boitumelo and Thato) responded as follows to the use of technology on campus:

For me,...it's my first time sitting in front of a computer.....

Computer is a serious problem.....I know nothing about the computer.

Fused learning. Education has evolved, and online education and technology-based learning seem to have become a norm at educational institutions, specifically HEIs. This makes it even more imperative that HEIs realize that not all students are computer or technology literate. Therefore, HEIs must move away from the false assumption that every student has access to computers or other forms of technology. HEIs need to prepare students well in advance in using technology and cannot assume that all students are technology savvy. Furthermore, blended learning has the potential to marginalize students because of their diverse backgrounds. Some students have inadequate computer training, while others have been exposed to computers from an early age. Therefore, from a functionalist perspective, when one part of the institution benefitted over another, the institution seems dysfunctional, and the equilibrium is affected. Students attested that some of them and many other UAP students have never used a computer before. It seems like some students experience use of technology more intense than others (Zizi and Thato):

...computer is going to damage my certificate...

\section{Computer is a serious problem.....I know nothing about the computer.}

Exposure to technology. Additionally, students indicated that the computer training module was offered in the second semester only, which posed a huge problem. They are expected to type assignments, complete online activities, and search for information on the Internet right from the beginning of their academic career. Therefore, their insufficient 
computer skills brought about unfavourable results, and at times, they had to pay someone to type their assignments.

\section{Physical Environment and Resources}

Campus segregation. Several universities in South Africa and across the world appear to have adopted access programs to address the issue of widening participation and to prepare students for mainstream education. However, it appears that institutions in South Africa that offer access programs do so at a different campus than the mainstream campus. This isolation and segregation harm UAP students as they are viewed as academically underprepared. What is problematic is the language used to define UAP students (Edward and Sizwe).

I personally think it would be better if we are all on the same campus, like the main campus, we are disadvantaged at UAP campus in terms of transport. We're mostly referred to the main campus for almost all services, and it's a lot.

When it comes to UAP, we don't have enough service delivery. We need.... more academic advice and tutors. So for me, if we all attend on one campus, I think that will help in service delivery.

Stigmatization. The language seems to cause further stigmatization. UAP students are referred to as under-prepared, at risk, coming from disadvantaged backgrounds, etc., adding this stigmatization is campus segregation and isolation. Below, students shared views on segregation of campuses (Thabang, Zizi, Luyanda and Mamello):

....some facilitators tell us that we are rejects, we have been rejected by the main campus, that we come to class to warm up chairs, that we are metals just sitting there with no response or understanding.

It is very painful when we are told that we are rejects... it's very painful, and it hurts.

It is not fun to be told that you are a reject, as some students ba e nka ka pelo (take it to heart).

Equal distribution of resources. The above responses show that the students are dissatisfied with the segregation of campuses as it denied them certain services, such as academic advising and tutors at the disposal of mainstream students. Consequently, it seems as if order and stability are not maintained within the institution, as resources are unequally distributed. Additionally, functionalists stated that one function of education is the equal distribution of resources; therefore, when an institution does not uphold this part of its function, the institution could be harmed as a whole. Even though most respondents seemed unhappy with the segregation of campuses, others seem content with the arrangement. However, there seems to be some consensus that some beneficial resources are only available at the mainstream campus, which is located far from their campus. Therefore, transport money becomes an issue.

In addition to the challenges students experience at UAP, some other experiences seem positive (Thabang and Luyanda):

Being in the program is fun. We experience new things such as diversity (new language, friends, independence from parents). 
I have learned two new languages, even though I am not fluent.

Independence. From these responses, it is evident that some students seem excited about new experiences that HE brought with, and they learned to make decisions that would enhance their progress and transition to mainstream. For others, being at UAP comes with unanticipated responsibilities (Zizi, and Thato):

For me, being in the program is sometimes kind of challenging, the workload....coming from high school, at school, we were spoon-fed given everything. Here, we have to be independent; everything is up to you. Whether you are attending or not, whether you submit your work or not, it's all up to you.

Workload, for me, ma'am, I tend to procrastinate, and when I procrastinate, workload piles up....., and it's very challenging.

However, they also indicated that they did encounter some challenges at the hands of their facilitators (Thabang):

some facilitators tell us that we are rejects, we have been rejected by the main campus, that we come to class to warm up chairs, that we are metals just sitting there with no response or understanding.

From the point of view of the students, being constantly reminded that they were not good enough to be there negatively affected their well-being and their studies and personal lives. Therefore, students indicated that they are reluctant to approach their facilitators when there were module-related matters that they did not understand. From a functionalist perspective, it is important that different parts within an institution function interdependently; otherwise, the entire system can be harmed, become dysfunctional, and expose part of the system to unintended consequences. This, in turn, can negatively impact students' dignity, progression, retention, and participation in HE. Therefore, the use of demeaning language potentially would negatively affect the students and the institution as a whole. Additionally, the use of such language might lead to lower retention rates, lack of motivation among students, and consequently tarnish the image of the institution.

Students did indicate appreciation for their facilitators. However, almost all students (Zizi, Thabang, Sizwe, Edward, Lydia, Kate, Luyanda, Boitumelo and Mamello) expressed discomfort experienced during sessions; that is, they have observed a lack of good working relations between their facilitators:

Our facilitators......we love them and respect them... it's like someone (facilitator) wants to prove a point to other..... as students. We are here to learn and need information and pass. You know, ma'am, soldiers work together and cover each other, but our facilitators don't cover each other....like they want to prove a point that someone did not prepare for their work. In the future, facilitators must act like soldiers.... 
I think they are not trained for combined classes.....azikwazi ukubusa izinkunzi ezimbili esibayeni esisodwa (translation - we can't have two bulls in the same kraal).

Training and facilitation. The above views indicate that the students valued good structure and expected their facilitators to be well-prepared. The students also stated that they would appreciate facilitators working as a team, not exposing and criticizing each other in front of students. They further indicated that the main reason for being at university was to learn, not to observe facilitators criticizing each other and wanting to prove that they have been facilitators for a long time. Students further indicated that they observed a lack of communication between facilitators, which they claimed to negatively impact their studies as they received mixed messages on how to address and answer test and exam questions. Consequently, due to observed behaviour among facilitators, students seem to be scared to ask questions for clarity, students seem to agree on this observation:

We are scared of asking questions when we do not understand. Facilitators show angry faces when we ask questions.(The rest of the co-researchers nodded. )

Sense of collegiality. The above responses demonstrate that when parts do not co-exist and function interdependently, harm can be caused. Therefore, due to the inability of facilitators to work as a team, students were confused. Moreover, students struggled with learning. Based on the above responses, facilitators need to provide comfortable space for an effective learning process. A space where no individual student feels threatened and no feeling of belonging. Therefore, this calls for integration among different actors, which implies collaborative functioning, associated with enhancing student learning and transition, thereby providing students a sense of collegiality.

\section{Learning Assistance Support Centre}

Learning assistance support centre is used to refer to not limited to physical space or building, but includes provision of services such as writing support which have the potential to enhance student retention and success.

Writing support. Some students at university struggle with academic-related matters, such as academic referencing, essay writing, and using IT. These struggles call for learning assistance support centers within the HEIs, particularly UAPs. The invisibility of learning assistance support centers seems to deny students the plausibility of realizing their potential and identifying areas that need development. HEIs bring their own set of challenges, for example, academic writing. Therefore, without learning assistance support centers, students might be overwhelmed and disconnected from the institution. Students responded as follows in terms of their awareness of the availability of a support center at the UAP campus (Sizwe and Zizi):

...do we even have such a building? As far I know, ma'am, the only support we have is our facilitators; that's if I can call it support.

...we don't have such a center because, like now, when we need someone to assist us with maybe writing an essay, we talk amongst each other.

You know what? I think the only place where we can get information is during class sessions..... 
Physical environment. From the above, it is clear that students needed assistance with academic writing. Therefore, if students had access to learning support centers, that will be beneficial. The same services are available at CTL at the University of the Free State. However, the CTL premises are situated on the main campus of UFS, which is quite far from the UAP campus. Therefore, the students are unable to access such support services. Students indicated that they need assistance in assignment writing, which one service that CTL renders to mainstream and extended program students. From a functionalist view, one function of educational institutions is to transmit skills to enable students to, later in life, contribute and function as part of society. However, the absence of a learning assistance support center at the UAP campus seems to threaten students from reaching their full potential.

Retention and success. Moreover, functionalism maintains that no individual can function in isolation; in other words, we need each other for the whole society to thrive. Unfortunately, from the students' responses, it seems as if they were forced to function in isolation. When an institution does not afford students access to learning assistance support centers, those students can potentially feel ill-prepared for the challenges posed by HEIs. This can eventually become a barrier to the retention and success of these students.

\section{Limited Access to Academic Advising}

Academic advisor refers to an individual assigned by an institution to assist student in the following areas: to navigate university culture, interdisciplinary agent with understanding of a particular faculty. Several scholars seem to concur with the benefits of academic advisors. One benefit is that academic advisors can inform academic staff of challenges students' face, which could hinder student performance. However, this kind of support service is limited at the UAP campus, and this is how students perceived academic advising on campus (Sizwe, Zizi, Edward, and Thabang):

We struggle to access academic advising services, as most of the time, the advisor is either fully booked for a month or the advisor has meetings or working at other campuses....

It is highly difficult to access an academic advisor. If we look at the number of students on this campus, you will see that everyone wants to access him, so it's difficult to use services. As at times, we still have to attend classes, and there is a long line. I also think this is too much work for the academic advisor as he is the only one advising students. This is too much work for one person if we look at the number of students at this academy.

Navigating university. From the students' point of view, UAP should involve or employ more academic advisors. Increasing the number of academic advisors can allow all students to have access to advice when in need of such services. Therefore, the accessibility of academic advisors would assist students in navigating HEIs and provide students with the necessary information to be successful, thereby growing a sense of belonging. However, limited access to such services might lead students to feeling neglect and working in isolation. Furthermore, when students have access to academic advisors, they could receive guidance in choosing courses that would provide knowledge to understand what they are studying and why, which would, in the end, enhance their engagement in the general education environment. 
Additionally, students can benefit greatly when they have a faculty-specific advisor to engage with throughout the year of study. In that way, students will benefit in that they will get correct information. However, students seem to have had a conflicting experience. They articulated that:

No...the information before the time when we register here at school, they said that when you want to do education, you can do Humanities. Recently now the information changed. They told us there are small changes that you can do education even here. The guy came from the main campus. He told us to continue with Humanities when we don't want to do humanities. It's painful ma'am, even our academic advisor tries to fight for us, but we are waiting with painful hearts. We still have that little hope that we are going to do education. I don't know whether it's a lecturer, or facilitator, or advisor. At the beginning of the year, during registration, they say that space is full for education. Next year, when I go to the Bloem campus, I will do education with no problem, but suddenly things have changed. They told us that we could continue with Humanities, then we can later do PGCE. I don't wanna do PGCE.

I am not going to do education next year. I wanna do nursing, but then apparently, I feel as if the university has deceived us, failed us, made empty promises regarding our education.... But, we were promised that when we are in this program, it will access us to higher learning.

Even in the small book, the yearbook, they said that for you to do social work, you must obtain seventy percent (70\%) in your modules, but they now say they don't take students from here (UAP).

Faculty specific. Some responsibilities of advisors include helping "make the implicit explicit, the hidden known, and the unfamiliar commonplace." However, based on the responses from the students, the inference can be that at the UAP, academic advisors did not make the "hidden known" to the students as seemingly, the students were promised that the UAP was the pathway for students to transition to the mainstream, where they could enroll for the courses of their choice. From the students' perspective, there seemed to be a lack of communication between the UAP academic advisor and the faculties. This lack of communication could be associated with one person having to do the work of twenty others, which can be quite overwhelming.

From a functionalist perspective, this lack of communication causes harm to those involved. In this case, the UAP students seem to be on the firing line. Therefore, the students suggested that UAP should increase the number of academic advisors so that everybody could get advice when needed. Unfortunately, the students felt that their own university did not provide them a sense of belonging. Through academic advising, UAP students could be in a better position to understand what they are studying and why. However, the students seemed to understand why they were enrolled in UAP, mainly because they did not meet the minimum requirements. 
Interdisciplinary agents. The students were in the dark about why they are in UAP enrolled for sociology and psychology because what was promised to them seemed not to possible at all. Students indicated that they were promised that upon successful completion of UAP, they could enroll in any field of their choice in the mainstream. However, based on the recent information, this seemed not to be the case at all.

\begin{abstract}
...this university is deceiving us, in that at the beginning of the year, we were promised that after completing UAP, we would be able to register for education at the main campus. Recently, this semester (second semester), people from the main campus came with DV2/3 forms for students to complete, and in that meeting, we were informed that students registered in Humanities would not be accepted for education in 2019. Ma'am, we are angry because we were promised that we would study what we want next year. If they told us this information at the beginning of the year, we would have made other decisions, or at least we will have known that there is no space for us in education. Now we are told that we will be competing with first-year students from matric, why will this UFS reject its own students? So, ma'am, this takes us back to facilitators saying we are rejects. It's like it's becoming true that we are rejects. And ma'am, I think between Bloem campus and South campus, someone is busy deceiving us because I know someone who was at South campus and is now doing education, so I think someone is deceiving us for the sake of new students coming from matric.
\end{abstract}

From the above responses, it seems that the implicit was not made explicit. Additionally, academic advisors as interdisciplinary agents can be of advantage to the co-researchers as they seem to understand the connection between what they are studying, and how one module can lead to the successful completion of another. As indicated above, the co-researchers are in a position to apply skills learned in a specific module to another module, such as the skills and competencies module to Sociology.

\title{
Discussion
}

HE students encounter a number of challenges before and after enrolment. Therefore, this study aimed to understand the challenges experienced by UAP students. Wilson-Strydom (2015) suggests that although participation in South African universities has improved, students have to be retained. The kind of support students are awarded plays an important role in their completing a HE qualification. This confirms that institutions need to be aware of and understand the experiences and challenges their students are facing, for instance, the nature of the academic support available, if any. Therefore, this study aimed to understand the kinds of challenges students experience in UAP.

For students to progress in their studies, there should not be any form of inequity in academic support such as mentoring and tutoring, peer support programs, and IT support. Additionally, preparatory support programs dealing with segregation of the program and its students, erecting learning assistance support centres, and improving academic advising services such as faculty specific academic advising, have to be in place. Therefore, coresearchers indicated academic support as invisible.

Karp et al. (2008) and Malthus (2015) suggest the availability and accessibility of mentors and tutors for students who need support. This sentiment is shared by Briggs et al. 
(2012) who found that students value access to tutorials. During the course of this study, the co-researchers needed to avail themselves for different sessions in order to participate in discussions. However, it seems as if the co-researchers found it critical that support services be available and accessible.

Although the office that the researcher and co-researchers worked in was uncomfortable, the co-researchers were allowed space to ask questions and seek clarity. It was also a space where they shared ideas with fellow group members to enhance their understanding of subject related material, for instance. As mentioned before, functionalism views one of the functions of education as to facilitate personal growth and the fair distribution of resources to all students (Ferrante, 2016). Therefore, by affording students resources can indicate that the institution is functional as its members are able to function and access such resources. For Jones and Lau (2010), it is important to ensure accessibility to resources by making such services relevant and supportive.

Although support services may be available to students, if such services are not explicitly made known to students and not incorporated in their formal timetables, students might hesitate to make use of those services. Students' past experiences do play a role in the learning process, for example, if a student has a background of being exposed to negative criticism, this might hinder learning. If support services are formal and structured, students might access these services and communicate with their peers without being embarrassed (Darling, 2015; \& Wanner \& Palmer, 2015). When support services are incorporated in the formal timetable of the university, students might feel compelled to access such services. Additionally, when these services are structured students might feel comfortable in exchanging knowledge and experiences with peers, which consequently might facilitate addressing the knowledge gaps experienced during lecturing sessions (Egan, 2015; Hakizimana \& Jürgens, 2013; \& Kaldi \& Griffiths, 2013). Access to structured and formalized services also facilitates independent learning as students are motivated to prepare for the exchange of knowledge during these sessions (Wanner \& Palmer, 2015). However, according to co-researchers, such structured services seemed unavailable in the UAP.

Hakizimana and Jürgens (2013), and Jones and Lau (2010) when affording student academic support, the atmosphere needs to entertaining, comfortable and supportive for all involved, that can enable social interaction and facilitates academic and social adjustment. Additionally, Harwood et al. (2015) indicate that when students are afforded a comfortable space for learning, such peer engagement may lead to an increase in confidence and thereby improve the learning process. Furthermore, to Speirs et al. (2017) it is important that students have a welcoming space where they can voice concerns related to subject matter without fear. Similarly, Waller et al. (2017) indicate that a supportive space affords students confidence to identify difficult subject matters and to seek assistance. This enables students to become change agents in learning, and enhance subject understanding, which facilitates independent learning (Wanner \& Palmer, 2015). However, the co-researchers seemed unsatisfied in terms of what they experienced during individual formal sessions. It is clear that during formal classes or sessions, the co-researchers were uncomfortable with their facilitators, a situation that could hinder the learning process. Co-researchers indicated "we are scared of asking questions, when we do not understand. Facilitators show angry faces when we ask questions".

Co-researchers confirmed and supported Hakizimana and Jürgens (2013), Jones and Lau (2010), Harwood et al. (2015), Speirs et al. (2017), Waller et al. (2017) and Wanner and Palmer (2015) assertions. That is, co-researchers' remarks suggested that during the course of this study, the atmosphere was entertaining, comfortable and supportive for all. They further articulated that they were able to engage with each other, which led to an increase in confidence that consequently enhanced the learning process. They also suggested that being part of this study was welcoming as they did not fear voicing concerns related to subject matters. Similarly, because of the supportive space they acted in, they were confident to voice concerns about 
difficult subject matters and not afraid to seek assistance. Due to the availability of a supportive space, they were enabled to engage in subject matters and formulate questions that helped them obtain good grades in that particular subject. Therefore, from the co-researchers' perspective, and in line with functionalism and PAR, it seems that working collaboratively in dealing with difficult matters was beneficial as the co-researchers were able to solve what they considered to be a problem.

Hakizimana and Jürgens (2013) believe that there is value in student collaborative learning. For example, in PTLEP, as in Supplemental Support Services (SSS), students are organized into small study groups of 5-7, which proved to be highly successful. Academic programs such as SSS were held close to the tests and examination, as it was the time when students are more focused on their learning, and have started to prepare for tests or examinations. Each group was facilitated by students who successfully completed the module, and this seems to have contributed to improved student academic performance and retention. However, in this study the researcher facilitated collaborative learning among students (coresearchers).

The co-researchers attributed their improved academic performance to access to SSS. In other words, working together with others motivated and facilitated active learning. Students were able to identify difficult course content, which was then discussed during SSS sessions, and that gave them the opportunity to pay attention to sections they did not understand prior to the session. In collaboration with the researcher, co-researchers (co-researchers \& researcher) who understood course content that others found challenging, were of assistance. That is, they explored challenging content by discussing questions together (Hakizimana \& Jürgens, 2013). This seemed evident in co-researchers response "we now know who is good at what module, and we work together".

At HEIs there are curriculum expectations and developments, therefore Wanner and Palmer (2015) suggest that institutions should encourage student engagement as this facilitates development of independent learners. Egan (2015) suggests that students develop their own goals and curricula, and these goals should be aligned with the expectations of the curricula, which will enhance independent learning. Seemingly, when students are involved in designing the curriculum, they have the opportunity to engage more with the material by spending time on challenging subject matters.

This potentially translate into students approaching the subject from different perspectives and engaging with others, which could facilitate higher order thinking. Darling (2015) concurs that when students are engaged in curriculum development and design, they adapt smoothly to the higher education community.

During the course of this study, co-researchers were encouraged to develop their own possible test questions and worked on how to answer these questions, thereby they were cograding and co-creating subject related matters. In a way, the co-researchers developed a question paper and a memorandum, and in the researcher's view, this facilitated the learning process. Therefore, when students are afforded space to collaborate and work as a collective, they learn better, and it increases their motivation and engagement during and after classes (Hakizimana \& Jürgens, 2013).

VLE provides a collaborative space where students work together on academic related matters, such as assignments, and discuss difficult course material (Im \& Kim, 2015). It seems as if the co-researchers continued academic related interactions offline, and in that way student engagement and learning outcome improved (Wanner \& Palmer, 2015). Online (on email and WhatsApp voice notes) material was made available for co-researchers

The co-researchers reiterated the usefulness of online platforms by stating access to and availability of such platforms afforded them space to continue interactions beyond the 
classroom. They further indicated that online platforms, to some extent, seemed to be supportive in nature, as students collaborated in dealing with difficult subject matters and supported each other while working on assignments. Additionally, access to online study guides assisted students on what to prepare for the next sessions. Therefore, working in collaboration with others seemed to provide the co-researchers a sense of being part of the campus community.

For Im and Kim (2015), ICT and blended learning (fused learning) seem to facilitate diverse online material. It appears that ICT and blended learning are student-centred, as facilitators make material available for students before the class commences. Facilitators also provide activity instructions before the class, and this provides students time to read the content before class and to ask questions during class sessions. Furthermore, students are expected to study the assigned reading materials available online, and their participation in small group discussion-type activities is vital and beneficial (Wanner \& Palmer, 2015).

The co-researchers seemed to support the views of Im and Kim (2015), and Wanner and Palmer (2015), with regard to access and availability of fused learning. For some coresearchers, the advantages of fused learning were that they could ask questions on challenging subject matters, and address any knowledge gaps. This fostered improvement in their academic performance. Other advantages of fused learning include that when students are online or logged on, they remember what is expected of them for the next session, as the information is in most cases posted on such platforms. Additionally, having access to fused learning provides space for students to share information on subject related matters facilitates growth, and leads to improved confidence and improved subject knowledge. However, other co-researchers due to "it's my first time sitting in front of computer" had to rely on classmates for assistance.

One of the skills HEIs seem to expect is that all new students know how to use a computer (Jones \& Lau, 2010; \& Im \& Kim, 2015). The students are expected to complete online assignments and engage in online discussions right from the start of their academic career (Hubackova \& Semradova, 2016). However, without prior training and knowledge, students tend to disengage from the institutional culture (Mitchell et al., 2014; \& Wanner \& Palmer, 2015). From the co-researchers' responses, it appears that not all students have been exposed to the use of technology prior to entering university, therefore technology use seem to pose some challenges.

Due to an increase in the use of technology in HEIs as suggested by Hubackova and Semradova (2016) and Smith et al., (2015), students entering without technological skills would find it even more challenging to adapt to the culture of the institution as they might be unable to complete online assignments and participate in online discussions, which ultimately would keep them from progressing academically. It might also have a negative impact on student confidence (Mitchell et al., 2014; \& Wanner \& Palmer, 2015). In an effort to address these issues and to advance the co-researchers' technological skills, the researcher took it upon herself to assist the co-researchers (students) with the basics aspects of using a computer. Collaboratively, the co-researchers worked on programs that were essential for their academic progression, namely creating Word and PowerPoint documents, searching for information on the Internet, and navigating through the institution's website to become familiar with Blackboard, the platform where they had to submit assignments, participate in online discussions and often complete assessments.

The co-researchers needed basic computer literacy training in order to complete assessments and perform better academically. Stewart and Zaaiman (2015), Radulović and Krstić (2017) and Ferrante (2016) suggest that, from a functionalist view, education needs to instil new values in students, namely the value of achievement and of equal opportunity. Therefore, discussing computer basics was one way in which the co-researchers could strive to succeed, as in their view it motivated them to learn more due to the support.

For students to share resources campuses need to be integrated. This integration of campuses might bring with equal distribution of and access to resources beneficial to students 
(Essack \& Quayle, 2007; Hlalele \& Alexander, 2012; \& Malthus, 2015). Additionally, the integration of campuses could provide students with a sense of belonging and inclusion (Akoojee \& Nkomo, 2007) that consequently might lead to students' easier adaptation to life at university and a better chance of succeeding in their academic endeavors.

Co-researchers were not satisfied with segregation of campuses as it denied them certain services, such as academic advising and tutors that seemed to be at the disposal of mainstream students. Additionally, when co-researchers needed to access said services, they were mostly referred to the mainstream campus as such services were unavailable at the UAP campus. One of the components of social justice in HE is equity, which in this instance aims to reduce the barriers that can impact on students' academic success (Guerra et al., 2020; Houdyshell \& Ziegler, 2020; Nelson \& Creagh, 2013; \& Rawlinson \& Willimott, 2016; Tarman \& Dev, 2018). Therefore, UAP students saw the segregation of campuses as threatening equity and as a result, posing barriers that could hinder success. Additionally, another reason that students called for the integration of campuses, is that they believed that such integration would help them understand their rights while they were on campus.

There is a need for equal distribution of resources across campuses, as these resources are beneficial to students. It seems as if the segregation of campuses brings about unfavorable consequences as not all students at the same institution of higher education have access to the same benefits. Furthermore, segregation of campuses seem to perpetuate the spirit of stigmatization, as sites where UAPs are offered are under-resourced, thereby hindering students from realizing their full potential and achieving academic success in the end (Hakizimana \& Jürgens, 2013; \& Mabila et al., 2005).

Nelson and Creagh (2013: 15) and Rawlinson and Willimott (2016) conceptualize social justice in HE as entailing participation and access, implying the inclusion of all groups and equal opportunity to utilize beneficial resources. Consequently, when all students are included in participation and have access to resources, equity is maintained and barriers to learning reduced.

Hlalele and Alexander $(2012,489)$ elucidate that "overcoming injustice means dismantling institutionalised obstacles that prevent some people from participating on a par with others as full partners in social interaction". In light of Durkheim's (in Ferrante, 2016) view, there seems to be a need in the UAP for integration among different actors. In the current research study, the students, the lecturers/facilitators, the tutors/mentors and campus resources are the actors. The researcher believes that integration among different actors imply collaborative functioning that enhances student learning and transition, thereby providing students a sense of collegiality.

According to Franklin and Blankenberger (2016), there is a need to improve academic support for UAP students. One mechanism that can direct the improvement of academic support is the availability of learning assistance support centres. Franklin and Blankenberger (2016) classify a learning assistance support centre as "a designated physical location on campus that provides an organised, multifaceted approach to offering comprehensive academic enhancement activities outside of the traditional classroom setting to the entire college community" (p. 4), and the availability of such centre is viewed as one of the best practice and critical resources that an institution can make available.

These centres provide a wide range of services in support of the mission of the institution, namely tutoring, study groups, support for special needs students, study skills instruction, writing assistance, math assistance, and computer assistance. The designed centres are available to students who did not meet the university's required admission score and the mainstream student population. 
Contrast to Franklin and Blankenberger's (2016) view as to what constitutes a learning support centre, for co-researchers a learning support centre meant the availability and accessibility of support. From co-researchers remarks, it seems as if they did not attach support centres to a physical building. They indicated that availability and accessibility of academic support within their reach were all that mattered. The co-researchers further suggested that it was not about the building, but about benefiting from the resources that mattered. From coresearchers' perspective, during the course of this study, they had benefited in that they were able to obtain support that enabled them to better their academic performance.

According to Peck et al. (2010), students benefit from ALSA as it affords them access to academic support associated with academic success. One of the aims of ALSA is to provide assistance with essay writing on a one-on-one basis and in a group setting. This is similar to LAC, mentioned in Arendale (2010). For Peck et al. (2010), ALSA involves different actors of which subject expertise is eminent. Involving subject experts is vital as they have clear understanding of the nature of essays for specific academic disciplines. They additionally have insight into the critical demands, use and understanding of the theories expected of the students.

During the course of this study, co-researchers received writing support such as assignment writing skills. This support was conducted in groups and on an individual basis. The co-researchers firstly worked as a group, thinking critically about their chosen topic. This shows that an element of peer learning was involved. The co-researchers submitted written assignments to the researcher for feedback. However, since the facilitators were the ones grading the assignments in the end, the researcher suggested a number of changes before the co-researchers submitted their assignments. The co-researchers were under no obligation to accept the researcher's suggested changes. From the co-researchers' written work and assignments, the researcher identified the following aspects that needed more attention, namely guidance on sentence structuring, grammar, punctuation and referencing. The co-researchers expressed their gratitude for deciding to accept the suggested changes.

Academic advising during group session entailed collaboration of co-researchers navigating university culture such as discussing other matters that seem challenging for students (Darling, 2015). In this instance, navigation of university culture means the understanding of general education and the courses that the co-researchers were enrolled for, focusing on interdisciplinary, integration and intentionality. It was important that the co-researchers understood the connection between different modules (Egan, 2015). For example, in the English module, the co-researchers were taught paragraph construction, and instead of realizing that this would help in writing assignments, test and exams of nearly all other modules, the coresearchers treated the modules as unrelated or in isolation. It seems as if most students struggled to apply knowledge or information gained in one module to another module as they regarded modules as separate units and not connected at all. Therefore, it was important that the co-researchers understood how modules are linked.

In Skills and Competencies for Lifelong Learning module, the co-researchers were taught various skills that could facilitate success in their academic and personal life (UFS, 2018). However, they seemed not to apply such skills in their studies, as they regarded knowledge gained in that module as only necessary to pass a module. Therefore, it was of the utmost importance that the co-researchers learn synthesis and to apply the knowledge gained in the skills module to the general education environment (Egan, 2015; \& Lowenstein, 2015). However, the researcher scheduled a meeting with the appointed academic advisor at the UAP to address the co-researchers' questions and concerns in terms of future enrolments or curriculum advice.

For Karp et al. (2008), the appointment of more advisors, particularly faculty specific advisors are vital. The availability of faculty specific advisors can provide students better understanding of fields of study, unlike students receiving advice from general advisors. As 
highlighted in Strayhorn (2014), the key responsibilities of advisors include making the implicit explicit, and the unknown known.

Darling (2015) views navigation of university culture as an understanding of general education and the courses that the co-researchers were enrolled for. In other words, one of the responsibilities of an academic advisor is to be an interdisciplinary agent, which in this context means helping co-researchers to understand the connection between different modules (Egan, 2015).

Through academic advising, UAP students are in a position to understand what they are studying and why, which would in the end enhance their engagement in general education (Egan, 2015; Kirk-Kuwaye \& Sano-Franchini, 2015; \& Lowenstein, 2015). Academic advisors as interdisciplinary agents can be of advantage to the co-researchers as they seem to understand the connection between what they are studying, and how one module can lead to the successful completion of another. As indicated above, the co-researchers are in a position to apply skills learned in a specific module to another module, such as the skills and competencies module to Sociology.

\section{Conclusion}

Presented data see to highlight the need to improve the academic support of students in UAPs. The following challenges were addressed: limited tutoring assistance. In this regard, it seem like tutoring service is invisible, invisible in that if such service is available, the information is not readily available to students. Need for peer support programs seem evident. Students need supportive space that allows for collaborative learning, and students' involvement as curricula constructors. Insufficient IT support has been identified, that is, students indicated that some have no prior experience with computer, therefore, that seemed to place them at a disadvantage. Institutions that offer access programs need to ensure inclusivity that talks against segregation and stigmatization. Increasing number of academic advisors is paramount, as academic advisors play a vital role in navigating university culture. Erecting accessible and visible learning assistance support center seem vital, as the center can provide variety of support services such as writing support. These areas are categorized as inadequate and hindering the learning process, and therefore were considered significant and critical components that UAPs need to strategize to enable a smooth transition, progression, retention, and qualification attainment.

After exploring the aforementioned challenges, HEIs that offer and those considering access programs need to realize that each year we encounter new cohort with different challenges. Therefore, different mechanisms for different cohorts are essential. Additionally, there seems to be the need for programs aimed at addressing challenges in different disciplines, similar to STEM. What still needs to be explored and/or clarified by STEMs particularly at schools is whether such schools consider student future career interests and prospects.

\section{References}

Aguilar, S., Lonn, S., \& Teasley, S.D. (2014). March. Perceptions and use of an early warning system during a higher education transition program. In Proceedings of the Fourth International Conference on Learning Analytics and Knowledge (pp. 113-117). ACM.

Akoojee, S., \& Nkomo, M. (2007). Access and quality in South Africa higher education: The twin challenges of transformation. SAJHE, 21(3), 385-399.

Arendale, D. R. (2010). Access at the Crossroads: Learning assistance in higher education. Jossey-Bass. 
Arnold, J., \& Clarke, D.J. (2014). What is 'agency'? Perspectives in science education research. International Journal of Science Education, 36(5), 735-754. https://doi.org/10.1080/09500693.2013.825066

Ary, D., Jacobs, L. C., Sorensen, C., \& Razavieh, A. (2010). Introduction to research in education (8th ed.). Cengage Learning.

Babbie, E. (2010). The practice of social research (12 $2^{\text {th }} \mathrm{ed}$.). Wadsworth.

Babbie, E., \& Mouton, J. (2005). The practice of social research. Oxford University Press.

Bathmaker, A. (2016). Higher education in further education: The challenges of providing a distinctive contribution that contributes to widening participation. Research in PostCompulsory Education, 21(1-2), 20-32. https://doi.org/10.1080/13596748.2015. 1125667

Benokraitis, N. V. (2016). SOC: Introduction to Sociology (Student Edition $4^{\text {th }}$ ed.). Cengage Learning.

Bicer, A., Lee, Y., \& Perihan, C. (2020). Inclusive STEM High school factors influencing ethnic minority students' STEM preparation. Journal of Ethnic and Cultural Studies, 7(2), 147-172. http://dx.doi.org/10.29333/ejecs/384

Briggs, A. R., Clark, J., \& Hall, I. (2012). Building bridges: Understanding student transition to university. Quality in Higher Education, 18(1), 3-21. https://doi.org/10.1080/ 13538322.2011.614468

Camarero-Figuerola, M., Dueñas, J.-M., \& Renta-Davids, A.-I. (2020). The relationship between family involvement and academic variables. Research in Social Sciences and Technology, 5(2), 57-71. https://doi.org/10.46303/ressat.05.02.4

Creswell, J. W. (2012). Educational research: Planning, conducting and evaluating quantitative and qualitative research $\left(4^{\text {th }} \mathrm{ed}\right.$.). Pearson.

Darling, R. (2015). The academic adviser. The Journal of General Education, 64(2), 90-98. https://www.jstor.org/stable/10.5325/jgeneeduc.64.2.0090

Egan, K. (2015). Academic advising in individualized major programs promoting the three I's of general education. The Journal of General Education, 64(2), 75-89. https://www.jstor.org/stable/10.5325/jgeneeduc.64.2.0075

Essack, Z. \& Quayle, M. (2007). Students' perceptions of a university access (bridging) programme for social science, commerce and humanities. Perspectives in Education, 25(1), pp. 71-84.

Ferrante, J. (2016). Sociology: A global perspective. Cengage Learning.

Franklin, D., \& Blankenberger, B. (2016). Program evaluation of community college learning assistance centers: What do LAC directors think? Community College Review, 44(1), 325. https://doi.org/10.1177/0091552115609998

Gale, T., \& Parker, S. (2014). Navigating change: A typology of student transition in higher education. Studies in Higher Education, 39(5), 734-753. https://doi.org/10.1080/ 03075079.2012.721351

Garbe, A., Ogurlu, U., Logan, N., \& Cook, P. (2020). Parents' Experiences with Remote Education during COVID-19 School Closures. American Journal of Qualitative Research, 4(3), 45-65. https://doi.org/10.29333/ajqr/8471

Glassman, M., \& Erdem, G. (2014). Participatory action research and its meaning: Vivencia, praxis, conscientization. Adult Education Quarterly, 64(3), 206-221. https://doi.org/10.1177/0741713614523667

Guerra, M., Lopez, M., \& Benavides, A. (2020). Funds of Identity and Education: The Journey of a Latina Educator from Linguistic Erasure to Linguistic Empowerment. Journal of Culture and Values in Education, 3(2), 100-119. https://doi.org/10.46303/jcve.2020.15

Gyamera, G. O. (2018). I just want to be somebody: exploring students' Motivations and experiences in universities. South African Journal of Higher Education, 32(3), 154 171. http://dx.doi.org/10.20853/32-3-2544 
Hakizimana, S. \& Jürgens, A. (2013). The Peer Teaching/Learning Experience Programme: An Analysis of Students' Feedback. Volume 9, pp. 99-127.

Hansen, J. D., \& Reich, J. (2015). Democratizing education? Examining access and usage patterns in massive open online courses. Science, 350(6265), 1245-1248. doi:: 10.1126/science.aab3782

Harwood, V., McMahon, S., O'Shea, S., Bodkin-Andrews, G. \& Priestly, A. (2015). Recognising aspiration: The AIME program's effectiveness in inspiring Indigenous young people's participation in schooling and opportunities for further education and employment. The Australian Educational Researcher, 42(2), pp.217-236.

Henslin, J. M. (2008). Sociology: A down-to-earth approach ( $9^{\text {th }}$ ed.). Pearson.

Hlalele, D. L. (2010). Do learning skills acquired in the university access programme enhance participation in academic practice? Faculty of Education, 24(1), 98-110.

Hlalele, D., \& Alexander, G. (2012). University access, inclusion and social justice. SAJHE, 26(3), 487-502.

Houdyshell, M., \& Ziegler, N. (2020). Graduate students share their experiences of building helping skills: A case study. Journal of Curriculum Studies Research. https://doi.org/10.46303/jcsr.2020.4

Hubackova, S. \& Semradova, I. (2016). Evaluation of Blended Learning. Procedia - Social and Behavioral Sciences, Volume 217, pp. 551-557.

Im, J. \& Kim, J. (2015). Use of Blended Learning for Effective Implementation of EnglishMedium Instruction in a Non-English Higher Education. International Education Studies, Vol. 8(11), pp. 1-15.

Jacobs, L. 2014. Research Matters. In Du Plooy-Cilliers, F., Davis, C \& Bezuidenhout, R. Eds. Claremont, Juta.

Jones, N., \& Lau, A. M. (2008). Blending learning: Widening participation in higher education. Innovations in Education and Teaching International, 47(4), 405-416. https://doi.org/10.1080/14703297.2010.518424

Kaldi, S., \& Griffiths, V. (2013). Mature student experiences in teacher education: Widening participation in Greece and England. Journal of Further and Higher Education, 37(4), 552-573. https://doi.org/10.1080/0309877X.2011.645468

Karp, M. M., O'Gara, L., \& Hughes, K. 1. (2008). Do support services at community colleges encourage success or reproduce disadvantage? An exploratory study of students in two community colleges. CCRC Working Paper No. 10. Columbia University. ED499920

Kirk-Kuwaye, M., \& Sano-Franchini, D. (2015). "Why do I have to take this course?" How academic advisers can help students find personal meaning and purpose in general education. The Journal of General Education, 64(2), 99-105. https://www.jstor.org/ stable/10.5325/jgeneeduc.64.2.0099

Lazar, M. M. (Ed.) (2005). Feminist critical discourse analysis: Gender, power and ideology in discourse ( $2^{\text {nd }}$ ed.). Palgrave Macmillan.

Loh, R. C.-Y., \& Ang, C.-S. (2020). Unravelling Cooperative Learning in Higher

Education. Research in Social Sciences and Technology, 5(2), 22-39. https://doi.org/10.46303/ressat.05.02.2

Lowenstein, M. (2015). General education, advising, and integrative learning. The Journal of General Education, 64(2), 117-130. doi:10.1353/jge.2015.0010

Mabila, T. E., Malatje, S. E., Addo-Bediako, A., Kazeni, M. M., \& Mathabatha, S. S. (2006). The role of foundation programmes in science education: The UNIFY programme at the University of Limpopo, South Africa. International Journal of Education Development, 26(3), 295-304. https://doi.org/10.1016/j.ijedudev.2005.08.004 
Mahlomaholo, S. (2009). Critical emancipatory research and academic identity. Africa Education Review, 6(2), 224-237. https://doi.org/10.1080/18146620903274555

Malthus, C. (2015). Changing spaces: writing centres and access to higher education. Higher education Research \& Development, 34(2), pp. 441-444.

Marais, F.C., \& Hanekom, G. (2014). Innovation in access: 25 years of experience in access programmes. In Annual Teaching and Learning Report 2014: Moving the needle towards success (pp. 10-12). University of the Free State: Centre for Teaching and Learning.

Marincowitz, G.J. (2003). How to use participatory action research in primary care. Family practice, 20(5), 595-600. https://doi.org/10.1093/fampra/cmg518

McFarlane, K. J. (2016). Tutoring the tutors: Supporting effective personal tutoring. Active Learning in Higher Education, 17(1), 77-88. https://doi.org/10.1177/ 1469787415616720

Mitchell, L. D., Parlamis, J. D. \& Claiborne, S. A., 2015. Overcoming Faculty Avoidance of Online Education: From Resistance to Support to Active Participation. Journal of Management Education, Vol. 39(3), pp. 350-371.

Monkeviciene, O., Vildziuniene, J., \& Valinciene, G. (2020). The Impact of Teacher-Initiated Activities on Identifying and Verbalizing Ways of Metacognitive Monitoring and Control in Six-Year-Old Children. Research in Social Sciences and Technology, 5(2), 72-92. https://doi.org/10.46303/ressat.05.02.5

Mountford-Zimdars, A., Sanders, J., Moore, J., Sabri, D., Jones, S., \& Higham, L. (2017). What can universities do to support all their students to progress successfully throughout their time at university? Perspectives: Policy and Practice in Higher Education, 21(2-3), 101-110. https://doi.org/10.1080/13603108.2016.1203368

Nel, C., Kistner, L., \& van der Merwe, E. (2013). Using enrolment trends to facilitate access. Journal of Higher Education Policy and Management, 35(1), 85-94. https://doi.org/10.1080/1360080X.2013.748480

Nelson, K. J., \& Creagh, T. A. (2013). A good practice guide: Safeguarding student learning engagement. The Queensland University of Technology. Retrieved October 22, 2020, from https://eprints.qut.edu.au/59189/

Nkonyane, V. (2014). Power knowledge contestations at a transforming Free State higher education institution: Learning guide as a metaphor. Higher Education of Social Science, 7(1), 14-21.

Northall, T., Ramjan, L. M., Everett, B., \& Salamonson, Y. (2016). Retention and academic performance of undergraduate nursing students with advanced standing: A mixedmethod study. Nurse Education Today, 39, 26-31. https://doi.org/doi:10.1016/ j.nedt.2016.01.010

Olga, K., Tarman, B. \& Stepanova, I. (2021). Education in the Context of Digitalization and Culture: Evolution of the Teacher's Role, Pre-pandemic Overview. Journal of Ethnic and Cultural Studies, 8(1), 226-238. http://dx.doi.org/10.29333/ejecs/347

O'Shea, S., Lysaght, P., Roberts, J., \& Harwood, V. (2016). Shifting the blame in higher education - Social inclusion and deficit discourses. Higher Education Research \& Development, 35(2), 322-336. https://doi.org/10.1080/07294360.2015.1087388

Palmer, D., \& Witanapatirana, K. (2020). Exposing Bias through a Deficit Thinking Lens Using Content-Analysis of Macro Level Policies. Research in Educational Policy and Management, 2(1), 23-39. https://doi.org/10.46303/repam.01.02.2

Pascoe, G., 2014. Research Matters. In: F. du Plooy-Calliers \& C. Davis, eds. Research Matters. South Africa: Juta.

Peck, J., Chilvers, L. \& Lincoln, Y. (2010). Learning support: Student perceptions and preferences. Art, Design \& Communication in Higher Education, 9(2), 135-149. https://doi.org/10.1386/adch.9.2.135_1 
Radulovic, L. M. \& Krstic, S. M., 2017. Social inequality in education analyzed within various theoretical frameworks. Philosopgy, Sociology, Psychology and History, 16(1), pp. $25-$ 36.

Rawlinson, C., \& Willimott, M. (2016). Social justice, learning centredness and a first year experience peer mentoring program: How might they connect? Journal of Peer Learning, 9, 41-48. https://ro.uow.edu.au/ajpl/vol9/iss1/5

Smith, J. A., Trinidad, S., \& Larkin, S. (2015). Participation in higher education in Australia among under-represented groups: What can we learn from the Higher Education Participation Program to better support indigenous learners? Learning Communities: Internal Journal of Learning in Social Contexts: Special Edition: Indigenous Pathways and Transitions into Higher Education, 17, 12-29. doi: 10.18793/LCJ2015.17.02

Speirs, N. M., Riley, S. C., \& McCabe, G. (2017). Student-led, individually-created courses: Using structured reflection within experiential learning to enable widening participation students' transition through and beyond higher education. Journal of Perspectives in Applied Academic Practice, 5(2), 50-57. https://doi.org/10.14297/ jpaap.v5i2.274

Stewart, P. \& Zaaiman, J. (2015). Sociology: A South African introduction. Stewart, P; Zaaiman, J (Eds) ed. Cape Town: Juta.

Strayhorn, T. L. (2014). Reframing academic advising for students success: From advisor to cultural navigator. NACADA Journal, 35(1), 56-63. https://doi.org/10.12930/ NACADA-14-199

Strydom, J. F., Du Plessis, M., \& Henn, M. E. (2016). Using evidence to develop high impact transition programmes. Journal for New Generation Sciences, 14(3), 233-246.

Strydom, H., Fouche, C.B., \& Delport, C.S.L. (2004). Research at grass roots: for the social sciences and human service professions.

Tarman, B., \& Dev, S. (2018). Editorial: Learning Transformation through Innovation and Sustainability in Educational Practices. Research in Social Sciences and Technology, 3(1), i-ii. https://doi.org/10.46303/ressat.03.01.ed

Tronto, Joan C. 2013. Caring democracy: Markets, equality, and justice. NYU Press

University of the Free State. (2018). Skills and competencies for lifelong learning. Compiled by L Rossouw, Department of Psycholoy. University of the Free State, Bloemfontein.

Van den Berg, C. L., Verster, B., \& Collett, K. S. (2018). Flipped out in the blended classroom, the good, the bad and the ugly: When academics become students. South African Journal of Higher Education, 32(6), 440-459. http://dx.doi.org/10.20853/32-6-2984

Van Rensburg, G. H., Botma, Y., Heyns, T., \& Coetzee, I. M. (2018). Creative strategies to support student learning through reflection. South African Journal of Higher Education, 32(6), 604-618. http://dx.doi.org/10.20853/32-6-2888

Waller, R., Mathers, A., Savidge, P., Flook, G., \& Hamm, D. (2017). Engaging sociologists: An A-Level tutoring and mentoring outreach project with 2nd year undergraduate students. The Sociology Teacher, 6(2), 4-11. https://www.britsoc.co.uk/media/ 24364/spring_2017_tst_vol_6_2.pdf

Wanner, T. \& Palmer, E. (2015). Personalising learning: Exploring student and teacher perceptions about flexible learning and assessment in a flipped university course. Computers \& Education, Volume 88, pp. 354-369.

Weninger, C. (2012). Codes as process. In L. S. Given (Ed.), The SAGE encyclopedia of qualitative research methods. SAGE Publications. Retrieved October 22, 2020, from https://edge.sagepub.com/system/files/Ch10CodesandCoding.pd

Wildemuth, B. M. (2009). Applications of social research methods to questions in information and library science. Westport, CT: Libraries Unlimited. 
Wilson-Strydom, M. (2015). University access and theories of social justice: Contributions of the capabilities approach. Higher Education, 69, 143-155. https://doi.org/10.1007/ s10734-014-9766-5

\section{Notes on Contributors}

Lerato M Sekonyela, is a Module Coordinator in the Department of Sociology, and Academic Facilitator at the Department of Psychology in University Access Programme at the University of the Free State (UFS) in South Africa. She teaches Skills and Competencies for Lifelong Learning. Her research interest(s) have centred on University Access Programme: students experienced challenges, and a strategy to improve the academic support of first-year students in a university access programme. Dr. Sekonyela received her PhD in Education with specialization in Higher Education Studies from University of the Free State in 2019. 